\title{
Elementos para a elaboração de um projeto de promoção à saúde e desenvolvimento dos adolescentes - o olhar dos adolescentes
}

\author{
Tools for planning a project to promote \\ adolescent health and development: \\ the adolescents' perspective
}

Gilson Maestrini Muza 1

Marisa Pacini Costa 2

1 Centro de Orientação Médico-Psico-Pedagógica, Secretaria de Saúde do Distrito Federal. SMHN Quadra 3, Conjunto A, Bloco 1, Brasília, DF 70707-700, Brasil.

gilmuza@linkexpress.com.br 2 Departamento de Saúde Coletiva, Faculdade de Ciências da Saúde, Universidade de Brasília. Campus Universitário, Asa Norte, Área Especial. marisap@inkexpress.com.br

\begin{abstract}
This qualitativestudy was developed with low-income teenage students from outlying cities around the Federal District, Brazil. The main objecti ve was to identify their opinions, feelings, and information concerning the community's reality in order to implement a project to promote health care in this age group. A focal group technique was used to collect data. Two focal groups of adolescents 13 to 17 years old were conducted. Resulting data were submitted to descriptive analysis. According to the findings, adolescents have limited opportunities to engage in leisure activities. Problems in the community include lack of security, unavoidable contact with violence, and drug abuse. Adol escents understand that such problems are due to the absence of an appropriate social context. They al so highlight difficulties in establ ishing healthy interpersonal relationships within their families. Their first feeling is one of disempowerment in dealing with prevailing conditions, but they also show willingness to become involved in community work.
\end{abstract}

Key words Adolescence; Health Promotion; Living Conditions

Resumo Trata-se de um estudo que busca apreender as opiniões, senti mentos e saberes dos adolescentes escolares sobre a reali dade vivida nas suas comunidades, com o propósi to de implantar um proj eto de promoção à saúde. Foi realizado um estudo qualitativo com adolescentes escolares de duas ci dades-satéli tes do Distrito Federal, Brasil. A col eta de dados foi conduzi da com a técnica do grupo focal. Foram realizados doi s grupos focais com adol escentes com idade 13 e 17 anos e os dados foram submetidos a uma anál ise descritiva. Os resultados mostram que para esses adol escentes as ocupações do tempo livre são escassas. A falta de segurança ea inevitável convi vência com a violência, assi m como, a disseminação do uso abusi vo de drogas são al guns dos problemas que enfrentam na comuni dade. Os adolescentes entendem que a determinação dos problemas com os quais convivem sustenta-se na inexistência de um contexto social minimamente adequado e nas difi culdades de estabel ecimento de rel ações interpessoais intrafamiliares saudáveis. Quando se trata do enfrentamento das condi ções atuais, o primeiro sentimento que emerge é de i mpotência, mas mostram ainda al guma disposi ção de envol vimento com o trabalho comunitário.

Palavras-chave Adolescência; Promoção da Saúde; Condições deVida 


\section{Introdução}

Estima-se que para o ano 2000, no Distrito Federal, o número de adolescentes - indivíduos com idade entre 10 e 19 anos - chegue próximo dos 450.000 , cerca de $21 \%$ da população (IBGE, 1994). Apesar da expressividade dos números, os adolescentes geram uma baixa demanda nos serviços de saúde, pois ainda figuram como o grupo etário mais sadio quando comparados com os demais grupos populacionais (Travassos \& Lebrão, 1998). Além disso, os jovens mostram uma elevada resistência a uma aproximação com as instituições de saúde, ao mesmo tempo que as instituições de saúde têm dificuldade em acolher os adolescentes que a procuram. Como conseqüência dessa baixa demanda, os adolescentes têm recebido pouca atenção das políticas públicas de saúde.

Quando se trata de patologias centradas no corpo físico, a rede pública de saúde possui recursos humanos e equipamentos para oferecer uma assistência adequada (Muza et al., 1997). Há, no entanto, um grupo importante de adolescentes cuja demanda centra-se em temas relacionados com as questões sócio-emocionais. Em sua maioria são eventos associados à expressão da sexualidade ou surgem como conseqüência do envolvimento com situações relacionadas à violência e ao uso e abuso de substâncias psicoativas. Indicadores de saúde revelam que esses fenômenos são mais prevalentes entre os adolescentes de populações de baixa renda (SES-DF, 1998). Além disso, há um claro consenso entre os profissionais de saúde que os agravos relacionados a esses eventos são bastante complexos e não existem na rede de saúde do Distrito Federal equipamentos nem recursos humanos suficientes para assistir à população de adolescentes com demandas relacionadas a essas questões. Ao mesmo tempo, reconhece-se há muito que a melhor forma de enfrentar esses agravos é a promoção da saúde dos adolescentes.

Promover a saúde tem por pauta a atenção ao desenvolvimento integral, contemplando: o cuidado com a qualidade das relações interpessoais; um aporte nutricional balanceado; boas condições de moradia e acesso aos serviços de saúde; o acesso à informação e à educação formal ou profissionalizante; e a prática de esportes e lazer para um bom desenvolvimento físico, emocional, intelectual e social.

O objetivo desse estudo é buscar informações com o propósito de orientar a elaboração de um projeto de promoção à saúde e desenvolvimento do adolescente, dentro do Programa de Saúde da Família (PSF) em duas comunidades de baixa renda do Distrito Federal.

\section{Metodologia}

\section{A escolha do método}

Ao propor uma ação de promoção à saúde do adolescente na comunidade, a responsabilidade de execução, no âmbito da saúde, recai sobre as equipes de ações básicas. Admite-se que três grupos são importantes na compreensão dos elementos associados a uma proposta dessa natureza: as famílias com adolescentes, os profissionais de saúde da família e os próprios adolescentes. Quando se trata de uma proposta de elaboração de ações de promoção à saúde, é fundamental uma aproximação com os conteúdos subjetivos dos atores sociais envolvidos. Primeiro, como forma de alcançar as impressões, opiniões, sentimentos e saberes dos diferentes grupos; depois, porque interessa conhecer quais os recursos e as dificuldades de cada um desses segmentos (pais, adolescentes e profissionais) em promover a saúde dos adolescentes na comunidade. A nosso ver a pesquisa qualitativa melhor instrumentaliza no desvendamento dessas questões.

Do repertório de procedimentos de pesquisa qualitativa, utilizou-se na condução deste estudo a técnica do grupo focal (Minayo, 1994; Carlini-Cotrin, 1996).

\section{Operacionalização do grupo focal}

Como estratégia de operacionalização do grupo focal identificamos informantes-chave (mínimo de seis e máximo de 14 pessoas) em cada grupo alvo das duas comunidades. O primeiro passo consistiu na identificação da escola representativa de cada comunidade. Em seguida, verificaram-se as salas que continham alunos dentro da faixa etária que compreende a adolescência. Nesse momento foi solicitado ao professor regente que selecionasse, com a ajuda dos próprios adolescentes, cerca de dez alunos para participarem de uma atividade em grupo com temas relacionados à família, adolescência e saúde. Recomendou-se que dessem preferência àqueles que mostrassem menos inibição e maior disposição em participar de uma atividade em grupo. Os encontros ocorreram em uma sala disponibilizada pela própria escola, com garantia de conforto e privacidade para o grupo.

Inicialmente, era feita uma apresentação formal do diretor e do observador do grupo focal. A seguir eram expostos os propósitos do encontro e solicitada a anuência de cada um dos presentes a participar da atividade. A dinâmica das sessões de grupo focal incluíram: (1) 
a apresentação dos participantes; (2) o aquecimento, utilizando uma técnica de dinâmica de grupo; e (3) a produção de conhecimento propriamente dita, seguindo um roteiro previamente elaborado. $\mathrm{O}$ roteiro de entrevista compunha-se de cinco questões, a saber: (1) Como os adolescentes ocupam o tempo livre? (2) Quais as principais dificuldades dos adolescentes? (3) Por que acontecem esses problemas? (4) Como esses problemas podem ser enfrentados? (5) O que vocês podem fazer? Ao final dos encontros, as fitas gravadas e as anotações feitas pelo observador e pelo diretor do grupo focal serviram de base para a análise e apresentação dos resultados.

\section{O grupo focal com adolescentes}

Os grupos focais com adolescentes foram formados valendo-se de algumas visitas a duas escolas nas comunidades de Sobradinho II e São Sebastião. Catorze adolescentes com idade entre 13 e 15 anos, de ambos os sexos, formaram o grupo de Sobradinho II e dez adolescentes com idade entre 15 e 17 anos, de ambos os sexos, formaram o grupo de São Sebastião. Os encontros aconteceram em uma sala cedida pelas escolas das respectivas localidades.

Procedeu-se a uma análise descritiva dos dados, e os resultados apresentados neste trabalho dizem respeito exclusivamente ao grupo focal com os adolescentes dessas duas comunidades.

\section{Resultados e discussão}

\section{Sobre a vida quotidiana na comunidade}

“Aqui não tem nada!" Uma alusão ao esporte e lazer.

O primeiro tema proposto aos adolescentes indagava sobre a ocupação do tempo livre, ou seja, que atividades eram desenvolvidas quando não estavam freqüentando a escola. As falas foram bastante distintas para cada sexo.

Os adolescentes do sexo masculino foram praticamente unânimes em indicar a prática de esportes e a permanência em casas de jogos eletrônicos como as duas atividades mais praticadas por eles na comunidade. Mas relatam que é comum, na utilização das praças de esporte, a ocorrência de conflitos entre grupos interessados em ocupar o mesmo espaço. A freqüências às casas de jogos eletrônicos é praticamente diária e, nesse espaço, convivem com adolescentes mais velhos e mais experientes. Para as adolescentes, as duas atividades mais referidas foram a freqüência à própria escola e a prática de esportes, porém a ocupação das quadras de esportes dava-se em menos oportunidades que os rapazes e só o faziam quando as mesmas estavam ociosas.

Os shows em praça pública, segundo os adolescentes, estavam intimamente associados aos atos de violência. As casas de música eram freqüentadas por grupos que a utilizavam como um espaço de confronto entre rivais e, comumente, faziam-no armados. Aos demais, resta o enfrentamento do risco, como atesta um rapaz: "A gente vai pensando que vai ter briga, confusão, tiroteio...” ou a evitação do risco, como comenta com resignação uma garota: “A gente não vai porquetem medo".

Quando os adolescentes discorrem sobre as atividades que desenvolvem na comunidade, descrevem-nas sempre como uma prática pouco organizada e, às vezes, conflituosas, mas o que prevalece mesmo é a ociosidade. Para as adolescentes a escola amplia a função meramente acadêmica e é vista também como um espaço de lazer. Na falta de espaços de lazer, as adolescentes requalificam a escola como um desses espaços, talvez o único. Pura sabedoria.

\section{Os problemas dos adolescentes na comunidade}

\section{“Que morram todos!!! A violência detodo dia”.}

De todos os problemas dos adolescentes de ambas as comunidades, a violência foi a questão trazida com maior dramaticidade. Os adolescentes sentem-se amedrontados e mostramse acuados em seus próprios domicílios por aqueles que hoje vêem-se envolvidos com a delinqüência. Um "toque de recolher" vem com o cair da noite e poucos se aventuram a percorrer as ruas da cidade.

A existência de gangues é uma realidade nessas comunidades e já é admitido sem reservas pelos adolescentes. Uma das primeiras conseqüências dessa realidade é a limitação na formação das turmas de adolescentes, que diferentemente das gangues, servem como um espaço transicional de emancipação e construção da identidade social, em que prevalecem sentimentos de amorosidade (Zimerman, 1997). Contrariamente, as gangues possuem uma hierarquia rígida, o controle é exercido pela força e a disposição para o confronto com outros grupos, é um dos motes mais prevalentes. Um dos entrevistados comenta: "O pessoal se encara pra tirar uma onda, ver quem éo mais forte!" Com freqüência, esses grupos andam armados a ponto de permitir a expressão, com ar desolado de um dos adolescentes entrevistado: "Ar- 
ma aqui écomo poeira!" A participação de adolescentes do sexo feminino nas gangues já não causa nenhum estranhamento. Todavia, elas adotam um comportamento menos violento quando comparado aos rapazes. Numa das comunidades onde a violência parece mais evidente, a pertinência da gangue a uma determinada área, rebatizada de "território", é a norma. Sob determinadas condições (geralmente à noite), toma-se posse do "território" e a presença de pessoas estranhas é vista como uma provocação ou ameaça e suscita, freqüentemente, uma reação violenta. Em circunstâncias como essa, o confronto entre grupos é inevitável ou até mesmo é buscado.

A convivência com a violência, nos níveis em que se encontra atualmente, acaba por determinar novas atitudes e comportamentos na relação com o outro. A ordem entre os adolescentes é não encarar ninguém, pois pode ser interpretado como uma provocação; quando provocado ou quando algo lhe é tomado não deve responder e nem reagir, que as conseqüências podem ser mais graves que a simples perda de um bem. Além de ditar normas de comportamento entre os jovens, a violência determina o enclausuramento de um grupo significativo de adolescentes e mesmo de adultos, restringindo seus espaços entre a escola (que admitem não ser tão segura) e suas próprias casas. Se esperamos que crianças e adolescentes desenvolvam um sentimento de cidadania, é inaceitável que convivam com a violência e a falta de segurança, como ponderam Cruz \& Minayo (1994).

A questão do uso de álcool e drogas é outro tema que ocupa boa parte das preocupações dos adolescentes da comunidade. O uso e o abuso de drogas são vistos como generalizados em ambas as comunidades, um fato corroborado pelo grande número de recipientes usados para acondicionar a merla (pasta base de cocaína) encontrados em becos e ruelas.

Há tempos tem-se notificado a aproximação cada vez mais precoce dos adolescentes com as substâncias psicoativas (Muza, 1997a). Mais preocupante, no entanto, é o fácil reconhecimento do envolvimento de crianças com o abuso e o tráfico de drogas, a ponto de exclamarem, sem titubeio: "Aqui, qualquer menininho compra. Compra não, vende!!!” Os adolescentes, de ambos os sexos, consomem drogas em qualquer lugar, até mesmo na porta da escola e ninguém tem receio de ser descoberto. "A metade dos nossos colegas já consumi ram!" ou “Quando tem trio elétrico aqui, você só vêa fumaça. É nego fumando (maconha) ou catingando (merla)!", arriscam alguns dos entrevistados.
Qualquer espaço da cidade é visto pelos adolescentes como potencialmente um ponto de consumo, troca e comercialização de drogas. O custo e a oferta de substâncias psicoativas já não são obstáculos à aproximação dos adolescentes com as drogas. Alia-se a isso, a constatação inquestionável do maior risco de desenvolvimento de uma dependência química quanto mais precoce o início do abuso de substâncias psicoativas. Esses elementos configuram um quadro bastante desalentador e impõe-nos, cada vez mais, a conviver com um número crescente de adolescentes alijados completamente do exercício da cidadania.

Embora as questões relacionadas com a sexualidade, saúde reprodutiva e DST/AIDS tenham sido introduzidas pelo facilitador dos grupos focais, percebe-se claramente, pelo volume de manifestações dos entrevistados - risos, troca de olhares, meneios de cabeça, comentários ininteligíveis, provocações - relativas à expressão da sexualidade, que o tema ocupa boa parte do pensamento do adolescente. Porém, a desinformação, o preconceito e a vergonha ainda dominam o cenário quando o assunto é sexualidade e saúde reprodutiva. Quando encorajados a comentarem o tema, fez-se um silêncio assustador. As adolescentes foram bem mais espontâneas que os adolescentes que titubeavam sobre o quê e como falar: “Ah, eu não sei se posso falar...!" ou "Como é mesmo o nome...?", quando queriam se referir ao órgão genital ou à relação sexual.

Não há dúvidas de que os adolescentes hoje falam mais sobre sexo com os pais do que algum tempo atrás. As adolescentes têm mais oportunidade de trocar informações sobre temas relacionados à sexualidade com suas mães. As conversas, contudo, transitam apenas pela superficialidade dos temas. Não existe um aprofundamento destas questões, assim como não há esclarecimento sobre a necessidade de alguns cuidados antes da iniciação sexual e de conhecer os métodos contraceptivos. Vejamos como se expressam a respeito: “Minha mãe nunca foi uma pessoa assim de conversar comigo. Ela tinha vergonha e eu também!; Sea mi nha mãe me visse com uma cami sinha ia ser a maior pagação!"

Nenhum dos adolescentes do sexo masculino soube descrever a utilização de um método contraceptivo de uso feminino. Quando indagados sobre como se usa camisinha as falas, em geral, evidenciam muitas dúvidas no modo de utilização. A começar pelo modo como rasgam o envelope até a idéia da necessidade de utilização de um lubrificante qualquer. 
No trato de assuntos relacionados com a sexualidade, os adolescentes têm recorrido aos irmãos mais velhos e outros parentes próximos. Os amigos mais experientes também são freqüentemente procurados, mas queixam-se de que as conversas começam com boa dose de interesse, tanto do emissor como do interlocutor, para posteriormente, descambar para vulgarizações que deixam sérias dúvidas sobre a validade do conteúdo e a seriedade do diálogo.

Com um ar bastante sério e com um certo constrangimento, um adolescente declarou que em conversas sobre sexo o pai ensina que "...os homens não devem perdoar as mul heres!”, numa alusão de que os rapazes devem manter relações sexuais com tantas garotas quanto possível. Ainda que seja um depoimento isolado, corrobora alguns aspectos que ressurgem em outros trechos das entrevistas: a assimetria na relação entre homens e mulheres e a freqüente troca de parceiros entre adolescentes. Como exemplo, podemos citar algumas falas: "Os me ninos seduzem as meninas prometendo namoro sério e depois que conseguem o que querem (sexo) jogam fora!; As meninas dão decima dos garotos e depois que transam saem contando tudo pras amigas!" No depoimento das garotas, não refutado pelos rapazes, os adolescentes do sexo masculino têm negligenciado o uso de camisinha nas relações sexuais e alegam razões vagas: "É como chupar bala sem tirar o papel!" "Quebra o clima!" Por outro lado, as adolescentes admitem a existência de uma dificuldade (controle) na utilização do preservativo: "Na hora do vamos ver ninguém lembra, pois se lembrasse não fazia!" Se a liberação sexual experimentada por grupos de adolescentes vem em substituição à antiga insatisfação cultural com a repressão sexual, para esses grupos, vem carregada com uma boa dose de risco.

Os avanços na abordagem pelos adolescentes de temas relacionados com a sexualidade são evidentes. Novos modos de relacionamento afetivo-sexual foram inaugurados, provocando modificações importantes nas relações de gênero, mas, ainda assim, é uma relação que continua assimétrica e bastante desfavorável para muitos jovens. A proporção de gravidez entre as adolescentes cresce ano a ano e a incidência de AIDS é cada vez maior entre os jovens e adultos jovens (SES-DF, 1999); evidenciando que o sexo desprotegido tem ocorrido em um período muito precoce.

Um estudo epidemiológico domiciliar sobre sexualidade e saúde reprodutiva realizado em uma comunidade de baixa renda no Distrito Federal verificou que o número de adolescentes que usa o preservativo cresceu, mas ain- da é pequeno se comparado com número de adolescentes com vida sexual ativa. Por outro lado, chega próximo de cem por cento a proporção de adolescentes que alega conhecer a AIDS, além de ser grande, também, a proporção de adolescentes de ambos os sexos que afirma conhecer algum método contraceptivo (GDF/FNUAP, 1998). Como tem sido apontado, só a informação não é suficiente, pois ambas, gravidez não planejada e AIDS, persistem grassando entre os adolescentes.

Os fragmentos de histórias de vida centrados na expressão da sexualidade dos adolescentes entrevistados revelam alguns elementos preocupantes: a iniciação sexual se dá de forma precoce para muitos adolescentes; inexiste um "espaço" acolhedor, tanto na escola como entre os amigos e familiares, para tratar de questões relacionadas à sexualidade e à saúde reprodutiva; e mais, a sexualidade ainda desperta medo e vergonha e continua associada a crenças infundadas. Tudo isso combinado expõe adolescentes ao risco de uma gravidez não planejada ou à contaminação pelo HIV e faznos acreditar que para muitos desses adolescentes a gravidez é inevitável e a AIDS um conceito abstrato.

\section{Sobre as determinações}

\section{"A desocupação institucional ea desocupação instituída". \\ O tema proposto nesse tópico trata das de-} terminações dos problemas dos adolescentes. A falta de segurança é percebida pelos adolescentes como uma das causas da disseminação da violência e abuso de drogas. Nos seus depoimentos, a polícia é cunhada de omissa, covarde e conivente com a violência, uma vez que posta-se como parceira daqueles que sabidamente têm envolvimento com a delinqüência. Quando esperam ou solicitam uma intervenção policial na iminência de um confronto entre adolescentes, apenas ouve-se: “Que morram todos!!!” ou “Deixa matar!!” O adolescente envolvido com a violência da delinqüência é visto pela polícia como um bandido nato, um não-sujeito, portanto, não detentor de direitos.

Os adolescentes entendem que a violência, o abuso de drogas e as conseqüências da inadequada expressão da sexualidade têm raízes na família. Eles admitem, por exemplo, que o comportamento atual dos jovens remete à primeira infância e aos modelos de educação adotados nessa fase do desenvolvimento humano e, sobretudo, ao modo como os pais agem e relacionam-se com os filhos. Vejamos como expressam-se a esse respeito: "Isso acontece por- 
que os pais não corrigem os fil hos quando fazem alguma coisa errada na infância!"; “Eu me espel ho na minha família. Vocêvêo queaconteceem casa e não vai fazer por aí!"

Esse debruçar sobre a família foca a atenção sobre algumas questões bastante interessantes. É no espaço familiar que as crianças experimentam as primeiras identificações e se apropriam de um modelo de família. No alheamento dos pais na relação com os filhos, a apreensão dos valores familiares e das normas de convivência social são negligenciadas. Nesse sentido, os pais têm dificuldades em perceber o grau de desenvolvimento dos filhos e, com isso, o estabelecimento de limites fica seriamente prejudicado. Um limite extremamente rígido ou extremamente frouxo prejudicam o desenvolvimento sócio-emocional de crianças e adolescentes (Muza, 1996). As falas dos adolescentes são elucidadoras: "A maioria dos moleques daqui saem de manhã e não dão satisfação pra mãe!; Ser liberal demais...não dizer onde vai, coisas assim....atrapalha". A ausência do pai, relacionada à gênese dos fenômenos que mais trazem agravos à saúde dos adolescentes, veio à tona como explicitado na fala de alguns jovens: "Eu acho que é a falta do pai, porque só a mãenão dá conta de educar os filhos!; Meu pai não liga, não está nem aí !" O reconhecimento da importância do pai no desenvolvimento emocional dos filhos está bem estabelecido atualmente (Aberastury \& Salas, 1991). Crianças que não desfrutam da presença do pai têm dificuldade de internalização de um pai simbólico capaz de representar a instância moral do indivíduo. A ausência manifesta-se tanto na dificuldade de exercer a autoridade na relação com o outro como na de respeitá-la, ocasionando, por sua vez, obstáculos para o enfrentamento e para a superação de conflitos, na dificuldade de se fazer escolhas, com conseqüente possibilidade de envolvimento em comportamentos de risco (Muza, 1997b).

Um outro elemento do espectro das relações familiares trata da dificuldade de comunicação entre os adolescentes e seus pais. Uma dificuldade que se acentua se os temas estão relacionados com as questões sobre sexualidade, violência e drogas, temas bastante atuais e que mobilizam os recursos emocionais dos adolescentes e dos seus pais. Os adolescentes contam: "Eu não converso abertamente com meu pai, nem com minha mãe!”; “Os pais não entendem os adolescentes!". O que merece destaque é o reconhecimento de que o vínculo estabelecido com os pais muitas vezes não é o que desejam. Se os pais não encontram recursos emocionais para estabelecer e/ou manter os laços com seus filhos, deve haver elementos de suas próprias histórias de vida e nos papéis sociais atuais que ajudem a entender o que se passa nessas famílias.

A falta de ocupação do tempo livre, seja em atividades de lazer ou um trabalho remunerado é veementemente colocado pelos grupos como outro elemento importante identificado como causa das dificuldades enfrentadas pelos adolescentes. Eles se referem a essa questão dessa forma: "Se um jovem quer trabal har enão arruma emprego, elevai é vadiar, não é?; Os que estão à toa só ficam pensando besteira. Quem trabalha é diferente!"

Em nenhum momento, qualquer um dos adolescentes associou o contexto social depauperado como gerador das dificuldades aqui relatadas, o que os afasta da compreensão das questões estruturais como um dos pilares da gênese dos agravos à saúde da família e do adolescente.

\section{Sobre o enfrentamento da realidade}

\section{"Sobrevivendo na selva inóspita...".}

As primeiras propostas que um dos grupos de adolescentes pôde verbalizar como forma de melhorar a qualidade de vida na comunidade, estavam associadas à idéia de abandonar o local onde vivem. Nesta comunidade o espaço em que habitam foi rebatizado com o sugestivo nome de "território", com o claro significado de algo que pertence e/ou está sob domínio de alguém. Num segundo momento, ainda com ares de pouco compromisso com a tarefa proposta, um dos adolescentes sugeriu a elaboração de um curso de sobrevivência na selva. Embora tenha causado uma explosão de risos, acaba mostrando o nível de adversidades com o qual os jovens que vivem nessas áreas lidam no enfrentamento do cotidiano em suas comunidades.

A ocupação do tempo livre dos jovens de ambas as localidades foi a proposta mais densamente sugerida como forma de melhorar a qualidade de vida na comunidade. Para os jovens de uma das localidades, a ênfase recaiu na criação de espaços comunitários para o desenvolvimento de atividades esportivas, produção e acesso à arte e à cultura, além da realização de cursos profissionalizantes; para os da outra comunidade, no entanto, os adolescentes enfatizaram a necessidade de criação de postos de trabalho. "A gente quer mesmo étrabalhar!", ponderam eles. O primeiro grupo de adolescentes aposta na via da inserção na cultura, o segundo aposta na via da inserção no mercado de trabalho. Tanto uma como a outra podem ser 
traduzidas como uma busca por reconhecimento social e ambas são exeqüíveis e legítimas.

O enfrentamento da vergonhosa desigualdade social brasileira permeia cada um desses temas: educação, cultura, trabalho. O otimismo que recai sobre a educação, postulado por Madeira \& Rodrigues (1998) como uma das vias mais promissoras no percurso desse enfrentamento, é alentador, mas é pouco em vista das brutais diferenças de oportunidade na formação acadêmica de muitos desses jovens. A exigência por trabalho, feita por esses adolescentes, talvez se comporte como uma forma rápida de minimizar as conseqüências do abismo sócio-cultural em que vive boa parcela da sociedade brasileira; porém, corre o risco de alimentar o círculo vicioso da miséria e da pobreza.

\section{Sobre a responsabilidade de cada um}

"Falando a mesma língua...".

Sem qualquer receio e repleto de desânimo, os adolescentes desvelam toda a impotência em lidar com a realidade dos jovens dessas comunidades. Assim se expressam quando o tema é a questão do uso e abuso de drogas na comunidade: "A gente não podefazer nada. Você não consegue fazer ninguém sair dessa. Ele (aquele que usa) équevai teconvencer a vir pra dele. Não tem jeito não!!"

Aos poucos, todavia, os adolescentes vão admitindo a importância da participação deles próprios na promoção à saúde e desenvolvimento dos jovens e não se furtam ao envolvimento em atividades dessa natureza. Para tanto, os adolescentes propõem-se a participar de campanhas educativas, de jovens para jovens, falando a mesma linguagem e criando espaços de reflexão de temas de interesse dos adolescentes. Afinal, é para onde se volta o olhar do adolescente: o desejo de aprender e de ser reconhecido e respeitado (Buratto et al., 1998).

Contudo, para que essa disposição gere ações verdadeiramente profícuas precisamos, desde já, deixar de olhar os adolescentes com os estereótipos desqualificadores (preguiçosos, drogados, violentos etc.) e passar a vê-los como parte da solução. O protagonismo juvenil em ações de saúde é uma realidade em vários países da América Latina. Trata-se de grupos de jovens que se organizam das formas as mais diversas e invariavelmente contam com a participação de agentes sociais instituídos (Suárez-Ojeda et al., 1992).

A força do protagonismo juvenil emerge como fonte da iniciativa, de expressão de liberdade e da assunção de um compromisso, ou seja, a ação parte dele mesmo, é produto de uma de- cisão consciente e é o próprio adolescente que assume a responsabilidade pelos seus atos. Mas nada disso valerá a pena se a participação não for autêntica ou o adolescente permanecer como uma figura meramente simbólica ou decorativa (Costa, 1999). Cuidar de cada um desses elementos significa abrir espaços de ação criativa e transformadora da realidade social.

\section{Considerações finais}

Talvez estejamos vivendo hoje uma época em que nunca tantos adolescentes se expuseram a tantas situações de risco, com conseqüências danosas para seu desenvolvimento integral. Não mais podemos insistir em olhar o comportamento de risco na adolescência, seja ele ligado à expressão da sexualidade, ao envolvimento com a violência ou ao abuso de álcool e drogas, pela ótica da medicina cartesiana. É premente entendermos que o sofrimento de uma parcela expressiva de adolescentes, sobremaneira daqueles que vivem em situação de miséria, tem raízes na história, na cultura e na sociedade. E mais, é premente entendermos que os prejuízos não se restringem unicamente ao adolescente - o que já é grave - mas alcança também a família e a sociedade.

Nessa aproximação que realizamos com os adolescentes pudemos, ouvir deles próprios as questões que mais os afligem. A ociosidade é a norma. Os espaços de lazer são escassos e, quando existem, vêm carregados de riscos. As gangues substituíram as turmas. A violência foi banalizada e não significa mais que um "tempero" nas relações entre grupos de jovens. $\mathrm{O}$ contexto social não atende às necessidades materiais, mina as relações afetivas e impede uma adequada expressão do papel de pais.

Sem dúvidas o panorama é desanimador; contudo, o alento vem dos próprios adolescentes. Com todas as adversidades, e apesar delas, os próprios adolescentes propõem atuarem como agentes de transformação dessa realidade. Resta acolhê-los e criar condições para reconstruir, junto com esses jovens, um novo caminho.

Se o PSF se propõe a ser um espaço de ações básicas e, portanto, de Promoção à Saúde, é indispensável uma aproximação com os pais dos adolescentes e com os profissionais de saúde envolvidos na atenção integral aos adolescentes, sem o que estaremos tratando com uma empobrecedora parcialidade um fenômeno bastante complexo. 


\section{Referências}

ABERASTURY, A. \& SALAS, E. J., 1991. A Paternidade. Um Enfoque Psicanalítico. Porto Alegre: Artes Médicas.

BURATTO, A. L. O.; DANTAS, M. R. C. \& SOUZA, M. T. A., 1998. Direção do olhar do adolescente. Focalizando a escola. Porto Alegre: Artmed.

CARLINI-COTRIN, B., 1996. Potencialidades da técnica qualitativa grupo focal em investigações sobre abuso de substâncias. Revista de Saúde Pública, 30:285-293.

COSTA, A. C. G. O., 1999. Adolescente como Protagonista. Cadernos Juventude, Saúde e Desenvolvimento. v. 1. Brasília: Ministério da Saúde.

CRUZ NETO, O. \& MINAYO, M. C. S., 1994. Extermínio: Violentação e banalização da vida. O impacto da violência social sobre a saúde. Cadernos deSaúdePública, 10(Sup. 1):199-212.

IBGE (Fundação Instituto Brasileiro de Geografia e Estatística), 1994. Projeção da População do Brasil para o Período de 1980-2020. Textos para Discussão 73. Rio de Janeiro: IBGE.

GDF (Governo do Distrito Federal)/FNUAP (Fundo de Populações das Nações Unidas), 1998. Sexualidadee Saúde Reprodutiva na Adolescência. Projeto Multissetorial Integrado. Relatório de Pesquisa. Brasília: GDF/FNUAP.

MADEIRA, F. R. \& RODRIGUES, E. M., 1998. Recado dos jovens: Mais qualificação. In: Jovens Acontecendo na Trilha das Políticas Públicas (E. Berquó, org.), pp. 427-498, Brasília: Comissão Nacional de População e Desenvolvimento.

MINAYO, M. C. S., 1994. O Desafio do Conhecimento. Pesquisa Qualitativa em Saúde São Paulo: Editora Hucitec/Rio de Janeiro: ABRASCO.

MUZA G. M., 1996. Al coolismo e Drogadição na Adolescência. Histórias deVida. Ri beirão Preto, 1996. Tese de Doutorado, São Paulo: Faculdade de Medicina de Ribeirão Preto, Universidade de São Paulo.

MUZA, G. M., 1997a. Consumo de substâncias psicoativas por adolescentes escolares de Ribeirão Preto. I - Prevalência do consumo por sexo, idade e substância. Revista deSaúdePública. 31:21-29.
MUZA, G. M., 1997b. Da proteção generosa à vítima do vazio. In: Exercício da Paternidade (P. Silveira, org.), pp. 143-150, Porto Alegre: Artes Médicas.

MUZA, G. M.; FIALHO FILHO, I. L. \& JESUS, M. A. L., 1997. Estudo de Demanda Espontânea de Adolescentes em 19 Centros de Saúde Brasília: Programa de Atenção Integral ao Adolescente, Secretaria de Saúde do Distrito Federal.

SES-DF (Secretaria de Estado de Saúde do Distrito Federal), 1998. Programa de Atenção Integral à Saúde do Adol escente. Os Adolescente no Distrito Federal. Alguns Indicadores de Saúde. Brasília: Núcleo Normativo de Saúde da Comunidade, Departamento de Recursos Médicos Assistenciais, Fundação Hospitalar do Distrito Federal. (mimeo.) SES-DF (Secretaria de Estado de Saúde do Distrito Federal), 1999. Sistema de Informações sobre Nascidos Vivos (SINASC) e Boletim de Informações sobre DST/ AIDS. Brasília: Departamento de Saúde Pública, Secretaria de Saúde do Distrito Federal.

SUAREZ-OJEDA, N; SILBER, T. J. \& MUNIST, M., 1992. Servicios para la atención de salud del adolescente. In: Manual de Medicina dela Adolescencia (T. Silber, M. Munist, M. Maddaleno \& E. SuárezOjeda, org.), pp. 601-629, Serie Paltex para Ejecutores de Programas de Salud 20. Washington, DC: Organización Panamericana de la Salud.

TRAVASSOS, C. \& LEBRÃO, M. L., 1998. Morbidade hospitalar nos jovens. In: Jovens Acontecendo na Trilha das Políticas Públicas (E. Berquó, org.), pp. 165-196, Brasília: Comissão Nacional de População e Desenvolvimento.

ZIMERMAN, D., 1997. Grupos espontâneos: As turmas e gangues de adolescentes. In: Como TrabaIhamos com Grupos (D. Zimerman \& L. C. Osório, org.), pp. 59-67, Porto Alegre: Artes Médicas.

Recebido em 15 de setembro de 2000

Versão final reapresentada em 3 de agosto de 2001

Aprovado em 9 de outubro de 2001 